\title{
DESAFIOS E MECANIMOS DE ENFRENTAMENTO NA RELAÇÃO ENTRE AGRICULTURA FAMILIAR E ALIMENTAÇÃO ESCOLAR
}

\author{
Carla Rosane Paz Arruda Teo* \\ Márcia Pozzagnol Mossmann** \\ Roberta Lamonatto Taglietti***
}

\begin{abstract}
Resumo
Este texto objetiva reconhecer os desafios que têm sido relatados na literatura quanto à inserção da agricultura familiar no mercado institucional da alimentação escolar e os mecanismos de enfrentamento e superação desses desafios que têm sido construídos. Realizou-se revisão narrativa da literatura com busca na Biblioteca Virtual de Saúde, no Google Acadêmico e no Scientific Electronic Library Online, cruzando-se "alimentação escolar" and "agricultura". Foram incluídos os materiais localizados que atenderam aos seguintes critérios: artigos, livros, dissertações, anais de eventos; formato completo, gratuito e on-line; publicados a partir de 2009; com aderência ao objetivo desta revisão. Entre os desafios que emergiram, destacam-se: logística, falta de assistência técnica e interesse de agricultores e/ou prefeituras, burocracia para habilitação dos agricultores e adequação às normas sanitárias, fragilidades das chamadas públicas, dificuldades financeiras, estruturais e de organização dos atores envolvidos com o PNAE, sua compreensão sobre o Programa e resistências às inovações. Quanto aos mecanismos de enfrentamento construídos, a literatura evidenciou: fortalecimento do diálogo, articulação intersetorial, apoio de instituições de ensino/pesquisa, assistência técnica e extensão rural, organização dos agricultores em associações/cooperativas, planejamento dialógico
\end{abstract}

\footnotetext{
* Nutricionista. Doutura em Ciências dos Alimentos. Docente do Programa de Pós-Graduação em Ciências da Saúde da Universidade Comunitária da Região de Chapecó (Unochapecó). Chapecó, Santa Catarina, Brasil. E-mail: carlateo@unochapeco.edu.br

** Nutricionista. Mestra em Ciências da Saúde. Programa de Pós-Graduação em Ciências da Saúde da Universidade Comunitária da Região de Chapecó (Unochapecó). Chapecó, Santa Catarina, Brasil. E-mail: marciapozzagnol@unochapeco.edu.br

*** Nutricionista. Mestra e Doutoranda em Ciências da Saúde. Programa de Pós-Graduação em Ciências da Saúde da Universidade Comunitária da Região de Chapecó (Unochapecó). Chapecó, Santa Catarina, Brasil. E-mail: rotagli@unochapeco.edu.br
} 
das chamadas públicas, aproximação entre gestores, Conselhos de Alimentação Escolar, agricultores e lideranças locais, investimentos estruturais do poder público e de agricultores/cooperativas e, sobretudo, vontade política. Apesar dos avanços observados, ainda é necessária maior aproximação entre gestores e agricultores, além de fortalecimento do Conselho de Alimentação Escolar, o que pode contribuir para a sustentabilidade da inserção da agricultura familiar na alimentação escolar.

Palavras-chave: Desenvolvimento Local. Programas e Políticas de Nutrição e Alimentação. Segurança Alimentar e Nutricional.

\section{Introdução}

A agricultura familiar, segundo Food and Agricultural Organization (FAO), tem sido reconhecida como importante mecanismo para conquistas no campo da segurança e soberania alimentar, assim como para a proteção da agrobiodiversidade e para o uso sustentável dos recursos naturais, para a valorização de alimentos tradicionais e para a preservação da pluralidade cultural, representando, ainda, uma oportunidade para impulsionar as economias locais (FAO, 2014). A agricultura familiar brasileira contempla grande diversidade cultural, social e econômica, variando do campesinato à pequena produção modernizada e consistindo em um meio de organização das produções agrícola, florestal, pesqueira, pastoril e aquícola, predominantemente dependente de mão de obra familiar (SILVA, 2011).

Um marco no contexto nacional de fortalecimento da agricultura familiar foi o Programa de Aquisição de Alimentos (PAA), instituído pela Lei no 10.696/2003 com o propósito de que o Estado assumisse conduta estratégica na comercialização da produção do agricultor familiar, incentivando a produção agropecuária e a manutenção de preços (BRASIL, 2003). O PAA possibilitou aos agricultores familiares participarem do mercado institucional, comercializando seus produtos (a preços mais remuneradores do que os tradicionais) para estados e municípios, que os destinavam a grupos vulneráveis à insegurança alimentar e nutricional, por meio do repasse 
como doação a entidades sociais, escolas, hospitais e também para a formação de estoques (BACCARIN et al., 2017).

A partir da experiência precursora com o PAA, a agricultura familiar chegou definitivamente à escola, no Brasil, como política pública, em articulação ao Programa Nacional de Alimentação Escolar (PNAE), no ano de 2009. O PNAE é o mais antigo programa social do Governo Federal brasileiro na área de alimentação e nutrição, sendo considerado um eixo das políticas públicas deste campo (SANTOS et al., 2007). O Programa, que teve origem na década de 1940 e seu marco legal instituído em 1955 (CHAVES et al., 2007), é reconhecido, segundo o Fundo Nacional de Desenvolvimento da Educação (FNDE), como um dos maiores do mundo na área da alimentação escolar, atendendo de forma universal aproximadamente 42 milhões de estudantes da educação básica no país, com um orçamento anual de 3,8 bilhões de reais (BRASIL, 2015a).

Desde sua criação até o presente, a legislação que ampara a execução do Programa vem se consolidando e tornando mais explícita a intencionalidade de constituir o PNAE como mecanismo de desenvolvimento local. De 1955 a 1993, a gestão do Programa era centralizada em nível federal e os alimentos eram comprados por meio de processos licitatórios, predominando os formulados e industrializados (TRICHES; SCHNEIDER, 2010). A partir de 1994, a gestão do Programa foi descentralizada, passando a ser responsabilidade das Secretarias de Educação dos estados e municípios. Este novo modelo possibilitou melhorar a alimentação fornecida aos escolares, ocorrendo uma redução na oferta de alimentos formulados, pré-preparados e desidratados, que predominavam nos cardápios (DOMENE, 2008; SPINELLI; CANESQUI, 2002).

Em 2009, a Lei no 11.947 instituiu uma revisão do marco legal do Programa, estabelecendo as novas diretrizes para a alimentação escolar, vinculando-a à agricultura familiar. Para favorecer essa articulação, ficou determinada a dispensa do processo licitatório convencional na aquisição de produtos 
da agricultura familiar para o PNAE, substituindo-o por um modelo simplificado, denominado de chamada pública, desde que os preços fossem compatíveis com os vigentes no mercado local, e que os alimentos e bebidas atendessem às exigências do controle de qualidade estabelecidas pelas normas sanitárias vigentes (BRASIL, 2009). O art. 14 da Lei tornou obrigatória a aplicação mínima de $30 \%$ dos recursos federais repassados pelo FNDE aos estados e municípios na compra de alimentos produzidos pela agricultura familiar local, explicitando ainda apoio ao desenvolvimento local sustentável (VILLAR et al., 2013).

Esse novo olhar para a alimentação escolar vem sendo referido na literatura internacional como Home-Grown School Feeding (HGSF), indicando uma combinação de incentivo à produção agrícola local com a qualificação dos programas de alimentação escolar, assumindo como premissa básica que a baixa produtividade, o frágil desenvolvimento de mercados agrícolas locais e os restritos resultados nutricionais e educacionais são mutuamente reforçados e determinam insegurança alimentar e pobreza (ESPEJO; BURBANO; GALLIANO, 2009; BUNDY et al., 2009). O HGSF constituiria um ponto de sinergia entre os objetivos de aumento da renda dos agricultores, de desenvolvimento local e de saúde pública por meio de programas de alimentação como o PNAE (TRICHES, 2015). É importante acrescentar que a experiência institucional brasileira, de readequação da alimentação escolar aos ditames do HGSF, tem servido de exemplo a outros países, em especial da África e da América Latina. Estes países têm se inspirado no Brasil para (re) elaborar e (re)construir seus programas de alimentação escolar com vistas a utilizar os mesmos recursos investidos na alimentação dos escolares para promover o desenvolvimento socioeconômico (FAO, 2013; TRICHES; SCHNEIDER; SIMÕES, 2013).

A esse propósito, esclarece-se que desenvolvimento local é um construto que pressupõe a inclusão social (SILVEIRA, 2010), indicando um modelo de desenvolvimento que 
supera as abordagens centradas nos fenômenos econômicos, incorporando dimensões sociais, políticas e ambientais (JARA, 1998). Dessa forma, promover o desenvolvimento local implica potencializar recursos, ativos, oportunidades e capacidades locais, pela ação sinérgica dos diferentes atores presentes no território, mobilizados por objetivos compartilhados (PIRES, 2010). Não se trata, portanto, de uma questão de escala, mas de iniciativas de natureza participativa que colocam a coletividade em movimento na direção de reconhecer e articular as potencialidades locais para promover inclusão social (BUARQUE, 1999).

Com essa intencionalidade explicitada na revisão de seu marco legal, o PNAE inaugura, em larga escala, um novo modelo de aquisições públicas no Brasil, cuja simplificação favorece o acesso de pequenos produtores a um relevante mercado institucional, contribuindo para o desenvolvimento local e para amenizar o êxodo rural. Na prática, atualmente, isso significa que em torno de um bilhão de reais (BRASIL, 2017) estão sendo aplicados anualmente na agricultura familiar, com vistas a promover desenvolvimento local sustentável, valorização das tradições culturais alimentares saudáveis e melhoria dos níveis de segurança alimentar e nutricional.

Nesse sentido, além de favorecer a produção local e estimular as cadeias curtas de abastecimento, a nova legislação do PNAE estabelece que, nas compras, devam ser priorizados públicos específicos, como os assentados da reforma agrária, quilombolas e indígenas, os que produzem de forma orgânica/ agroecológica e os organizados em cooperativas ou associações, nesta ordem. Isso significa que a Lei incorpora questões socioculturais, organizativas e ambientais como balizadoras das compras institucionais de agricultores familiares (BACCARIN et al., 2017).

Reconhece-se, atualmente, que essa articulação entre a agricultura familiar e a alimentação escolar tem se traduzido na presença de alimentos produzidos localmente no ambiente da escola, por meio de sua inserção nos cardápios do PNAE (SARAIVA et al., 2013). Salienta-se, ainda, a expectativa 
de potencializar a inserção de alimentos menos processados na alimentação escolar a partir da Lei no 11.947/2009, respeitando os hábitos regionais e incentivando o consumo de alimentos mais saudáveis (BRASIL, 2009).

Contudo, a despeito da reconhecida intencionalidade desta Lei em reduzir a oferta e, consequentemente, o consumo de alimentos menos saudáveis na alimentação escolar (TEO; MONTEIRO, 2012), tem sido relatada a aquisição excessiva de alimentos ricos em gorduras e açúcares da agricultura familiar, tais como salames, bolachas, geleias e similares, em alguns locais. Essa prática permite, ao gestor técnico do Programa, cumprir mais prontamente com o requisito de destinar 30\% dos recursos federais recebidos à agricultura familiar, mas contraria o que dispõe a Lei sobre a compra de alimentos saudáveis destes fornecedores, preferencialmente orgânicos, como frutas e hortaliças (MOTTER; TEO, 2012).

Pondera-se, outrossim, que a Lei $n^{\circ} 11.947 / 2009$ possa ser implementada de maneiras diferentes, de acordo com a leitura que façam dela os diferentes atores sociais envolvidos, segundo as oportunidades que historicamente acessaram e de acordo com as capacidades que tenham desenvolvido, além dos interesses e disputas que estejam colocados em cena. Propõe-se, ainda, que essas diferentes leituras possam repercutir em situações mais ou menos exitosas no processo de dar materialidade à política (MOSSMANN; TEO, 2017).

Há que se considerar também que, em algumas regiões, a agricultura familiar não vem apresentando capacidade de produção compatível com as demandas do PNAE, sendo necessária a criação de incentivos nesta área para promover uma maior inserção desses alimentos na alimentação escolar (SANTOS et al., 2014). Além disso, um desafio relevante que precisa ser enfrentado pelos agricultores familiares diz respeito à divulgação das chamadas públicas para a aquisição desses gêneros alimentícios, já que muitos municípios ainda não as divulgam de forma ampla e, deste modo, os produtores não acessam a informação adequada em tempo hábil para participarem do processo (VILLAR et al., 2013). 
Nesse contexto, ainda que o mercado institucional representado pelo PNAE se constitua como uma grande oportunidade de sinergia entre os campos do desenvolvimento e da saúde, a atitude de inserir-se nesse mercado implica uma tarefa desafiadora para os agricultores familiares, pois o Programa possui uma complexidade própria, com uma variedade de especificidades. Conhecer esses desafios e compreender como têm sido desenvolvidos mecanismos para o seu enfrentamento pode contribuir para produzir novos avanços e fortalecer a inclusão da agricultura familiar nesse novo mercado (REINACH; CORÁ; BONDUKI, 2012).

Nesse sentido, o que se pretende com este texto é reconhecer os desafios que têm sido relatados na literatura no que tange à inserção da agricultura familiar no mercado institucional da alimentação escolar, assim como os mecanismos de enfrentamento construídos para a superação desses desafios.

Para tanto, foi realizada uma revisão narrativa da literatura (BRUM et al.,2016), com busca on-line desenvolvida na Biblioteca Virtual de Saúde (BVS-BIREME), Google Acadêmico e Scientific Electronic Library On-line (SciELO), em julho de 2017. Foi utilizado, nessa busca, o cruzamento do descritor "alimentação escolar" com o termo "agricultura", mediado pelo operador lógico and.

O corpus de pesquisa foi constituído pelos materiais bibliográficos assim localizados e que atendessem aos seguintes critérios de inclusão: artigos científicos, livros, dissertações e anais de eventos, passíveis de obtenção em formato completo e gratuito on-line, publicados a partir de 2009, ano em que se tornou obrigatória a utilização de, pelo menos, 30\% dos recursos repassados pelo FNDE aos municípios para a compra de alimentos provenientes da agricultura familiar.

A partir da leitura dos materiais localizados, foram selecionados aqueles que apresentavam aderência ao objetivo deste estudo, abordando os desafios e os respectivos mecanismos de enfrentamento construídos na relação da agricultura familiar com a alimentação escolar. Para a análise 
dos dados, foram extraídas dos materiais selecionados informações relativas ao objetivo desta revisão.

\section{Desafios à inserção da agricultura familiar na alimentação escolar}

Atualmente, as compras institucionais constituem uma das mais significativas políticas públicas para a agricultura familiar. Contudo, há que se considerar que os agricultores enfrentam desafios no fornecimento de alimentos para o PNAE, principalmente no que se refere à regularidade de produção, logística, quantidade de alimentos produzidos, qualidade e questões sanitárias, burocracia e falta de planejamento. A logística aparece como um dos maiores desafios para os agricultores familiares, pois são poucas as prefeituras que se dispõem ou têm condições de disponibilizar transporte para as mercadorias ou arcar com o seu frete. Da mesma forma, os agricultores geralmente não têm estrutura financeira para terceirizar este serviço ou para adquirir um veículo de porte adequado (BAVARESCO; MAURO, 2012).

Nessa direção, estudo realizado por Baccarin et al. (2012) avaliou as chamadas públicas para a aquisição de gêneros alimentícios da agricultura familiar para a alimentação escolar no estado de São Paulo no ano de 2011 sob o ponto de vista de sua adequação às demandas do setor. Nesta oportunidade, os autores constataram um elevado número de pontos de entrega em $40 \%$ dos editais avaliados, estimando-se que, em face das dificuldades de logística supracitadas, este achado representa uma barreira significativa para os produtores.

Para minimizar as dificuldades relacionadas à logística, a Resolução CD/FNDE no 4/2015 estabeleceu que os custos com embalagem e transporte devem ser considerados na definição do preço do produto (BRASIL, 2015b). Contudo, isso parece não estar sendo suficiente, pois a maioria dos agricultores familiares não dispõe de capital de giro para arcar com essas despesas até receber o valor correspondente à venda para o PNAE. 
Em estudo realizado por Prado et al. (2013) em duas cidades do estado de Minas Gerais - Betim e Contagem verificou-se que ambos os municípios não estavam realizando a aquisição mínima da agricultura familiar como prevê a legislação. Esse cenário esteve relacionado a dificuldades de logística decorrentes de uma alta demanda de produtos, a qual os agricultores locais não estavam preparados para atender. A carência de assistência técnica e capacitação aos agricultores, assim como sua baixa escolaridade, foram apontadas, nestes municípios, como as principais dificuldades para o atendimento do percentual mínimo determinado pela legislação.

Salienta-se que, no estudo de Saraiva et al. (2013), realizado a partir de dados de todas as regiões do Brasil sobre a compra de alimentos da agricultura familiar para o PNAE, identificaram-se como dificuldades a inviabilidade de fornecimento regular e constante de produtos, a falta de interesse dos agricultores e a demora das prefeituras em elaborar a chamada pública.

Estudo sobre a reflexão de agricultores familiares acerca da participação no PNAE, realizado por Marques et al. (2014), no município de Araripe (CE), identificou como desafios para a efetivação da compra da agricultura familiar para o PNAE questões relacionadas ao pagamento, estrutura física e transporte adequados para o armazenamento e distribuição dos alimentos.

Outro estudo, realizado por Triches e Schneider (2012) em Rolante/RS, constatou algumas barreiras existentes e as interfaces necessárias para a efetivação da compra de gêneros da agricultura familiar para a alimentação escolar, sendo elas: a burocracia dos trâmites, a organização dos agricultores e a formalização das agroindústrias. Cabe destacar que, com a aprovação da Lei no 11.947/2009, o processo licitatório foi substituído pela chamada pública para a compra de alimentos da agricultura familiar, minimizando, mas não extinguindo, as dificuldades burocráticas relacionadas com essa etapa do processo.

Vale ressaltar que outros estudos, como o de Triches e Schneider (2010) e o de Baccarin et al. (2011), também 
evidenciaram dificuldades relativas a logística, burocracia dos processos e, principalmente, organização dos agricultores como desafios que ainda necessitam ser superados para que os agricultores familiares ocupem efetivamente este mercado. $\mathrm{Na}$ mesma direção, destaca-se o estudo de Belik e Chaim (2012), no qual foi constatado que os agricultores familiares não conseguiam atender à demanda do município de São Bernardo do Campo/SP e à qualidade dos produtos, que muitas vezes era inferior ao padrão solicitado.

Trabalho de Gregolin et al. (2016), que teve por objetivo avaliar a implementação da Lei no 11.947/2009 nos 42 municípios do Território Sudoeste do Paraná no ano de 2011, indica que para 18 municípios a principal dificuldade foi a falta de interesse dos agricultores, assim como a falta de articulação entre as Cooperativas da Agricultura Familiar e a Municipalidade. Além disso, foi mencionada a baixa qualidade e variedade dos produtos, a falta de padronização de embalagens e rótulos, além das inadequações no transporte. Ainda no trabalho deste autor foram registradas várias intercorrências relativas à logística, sendo a principal delas o cumprimento do cronograma, indicando que os desafios para consolidação da agricultura familiar como principal fornecedora de alimentos para a alimentação escolar não se restringem apenas à entidade executora, pois os agricultores também precisam desenvolver estratégias de fortalecimento para atender às demandas administrativas e de produção (GREGOLIN et al., 2016).

Já segundo Souza (2012), em relato sobre o trabalho desenvolvido pelo Projeto SP Nutre em três regiões do estado de São Paulo - Vale do Ribeira, Bragança Paulista e Sudoeste Paulista - acerca do fornecimento da agricultura familiar para o PNAE, as dificuldades enfrentadas pelas organizações da agricultura familiar referem-se à adequação à legislação para obter a Declaração de Aptidão ao Pronaf (DAP); pequena diversidade de produtos, pois o agricultor tende a concentrar a produção em gêneros para os quais tenha garantia de comercialização; organização das operações 
logísticas, envolvendo principalmente o sistema de entrega e as embalagens dos produtos; e gestão do empreendimento e planejamento das ações.

O estudo de Silva, Dias e Amorim Junior (2015) sobre as mudanças organizacionais em empreendimentos da agricultura familiar do município de Espera Feliz (MG) identificou como a principal dificuldade o não atendimento às exigências sanitárias com relação ao processamento, armazenamento e transporte das mercadorias, que comprometia a obtenção dos registros sanitários para produtos específicos.

Resultado semelhante foi encontrado por Soares et al. (2015), em estudo realizado em um município do estado de Santa Catarina, sobre as potencialidades e dificuldades para o abastecimento da alimentação escolar com alimentos da agricultura familiar, sendo identificados problemas com a qualidade dos produtos, devido ao não cumprimento das exigências regulatórias para a comercialização de alimentos processados.

Estudo de Cavalheiro, Senna e Ribeiro (2016) analisou o fornecimento de produtos da agricultura familiar para o PNAE em São Gabriel/RS, tendo apontado que, para os agricultores, as principais dificuldades encontradas foram relativas ao atendimento aos requisitos de higiene e sanidade e o elevado custo com combustíveis, máquinas e transporte.

Nesse ponto, salienta-se que a efetivação das compras públicas, no Brasil, vem enfrentando um desafio relevante representado pelas exigências e regulamentações sanitárias, fiscais e ambientais nacionais, as quais estabelecem determinações a serem cumpridas para que os produtos alimentícios possam ser comercializados nos mercados institucionais. O principal aspecto dificultador reside no fato de que essas normativas tratam de forma semelhante o pequeno agricultor familiar e a grande indústria de alimentos. As dificuldades relacionadas à legislação sanitária incidem, principalmente, sobre a comercialização de produtos de origem animal, como carnes e laticínios (TRICHES; BACCARIN, 2016). 
Destaca-se que, no estudo de Bevilaqua e Triches (2014), realizado em dois municípios do estado do Paraná, foram identificadas dificuldades quanto à falta de organização dos agricultores, em um município de grande porte, para atenderem à demanda de produtos. Já no município de pequeno porte, as autoras referiram que muitos agricultores apresentavam resistência em participar do PNAE devido às exigências sanitárias de inspeção, rotulagem e embalagem, preferindo comercializar seus produtos em outros canais, como o PAA, por considerarem seu nível de exigência menor.

Corroborando esses achados, Triches e Kilian (2016), a partir de estudo realizado com diferentes atores envolvidos com a execução do PNAE, sugerem que o tamanho populacional dos municípios influencia no atendimento à resolução que prevê o percentual mínimo para compra de alimentos da agricultura familiar. Municípios maiores apresentam histórico de não atendimento à normativa, enquanto municípios de médio e pequeno porte normalmente atendem ou se aproximam do percentual mínimo. As autoras ponderam que a maior proximidade dos atores envolvidos com a execução do PNAE facilita as relações de trabalho, o que ocorre de maneira mais complexa e distante em municípios maiores.

Além disso, o estudo de Bevilaqua e Triches (2014) apontou a carência de envolvimento dos gestores e agricultores com o Programa como uma dificuldade a ser superada, devido à incipiente percepção desses atores sobre a finalidade do PNAE em estimular o desenvolvimento local e a promoção da saúde. Nesse sentido, observou-se que o município de pequeno porte concentrava esforços em atender o percentual de compra determinado pela legislação, mas desenvolvia o processo ainda sob a forma de licitação na modalidade pregão presencial, ignorando uma das principais inovações da Lei no 11.947/2009, que é a realização de chamadas públicas. Além disso, a assistência técnica, considerada insuficiente, foi apontada como uma dificuldade em ambos os municípios pesquisados, sendo ressaltada a falta de apoio da Assistência Técnica e Extensão Rural (ATER) com relação à organização da produção (BEVILAQUA; TRICHES, 2014). 
Essa mesma dificuldade foi relatada no estudo de Mosimann (2014) sobre os desafios e as potencialidades da articulação entre agricultura familiar e alimentação escolar em três municípios de Santa Catarina, principalmente com relação à produção orgânica, processo ao qual alguns agricultores procuraram aderir. Nesse caso, a escassez de assistência técnica foi considerada um dificultador para a obtenção de certificação, o que possibilitaria uma melhoria nos preços obtidos pelos produtos, considerando que a Resolução no 26/2013 (BRASIL, 2013) estabelece que os produtos orgânicos possam ter um acréscimo de até 30\% sobre o seu valor de venda em relação aos preços estabelecidos para produtos convencionais.

A falta de articulação e interação entre Secretaria de Agricultura, Empresa de Pesquisa Agropecuária e Extensão Rural de Santa Catarina (EPAGRI) e cooperativas foi também apontada como um desafio no estudo supracitado, comprometendo a relação entre oferta e demanda para o PNAE, bem como a inclusão de uma maior diversidade de alimentos produzidos localmente nos cardápios escolares (MOSIMANN, 2014).

Acerca dos obstáculos encontrados para a efetivação da Lei no 11.947/2009, Silva et al. (2013), em estudo realizado com agricultores familiares de 20 municípios do estado de São Paulo, verificaram que $23 \%$ dos agricultores citaram como dificuldade a ausência de capacitação dos atores envolvidos. Os autores destacaram, ainda, a existência de conflitos entre gestores do PNAE e agricultores, na medida em que os primeiros apontaram a falta de organização dos agricultores, enquanto os agricultores indicaram carência de apoio da prefeitura, ficando evidente a escassez de conhecimento dos problemas enfrentados por ambas as partes e a inexistência de diálogo.

Assim, cabe destacar que as dificuldades operacionais têm se apresentado como um grande desafio para a aquisição de produtos da agricultura familiar para o PNAE. As despesas para o produtor com embalagens, logística, custos com a 
participação em associações e cooperativas podem contribuir para que muitos deles, e suas organizações, deixem de participar do PNAE, mesmo aqueles que teriam capacidade produtiva para atender à demanda (TRICHES; BACCARIN, 2016).

Estudo realizado em dez municípios localizados no circuito das frutas no estado de São Paulo constatou que três deles (Valinhos, Indaiatuba e Itupeva) não adquiriram qualquer produto da agricultura familiar entre 2010 e 2012, creditando essa situação à falta de interesse do setor público municipal na aproximação entre agricultura familiar e alimentação escolar (SOUZA-ESQUERDO; BERGAMASCO, 2014). Já Saraiva et al. (2013), em pesquisa similar realizada com dados de todas as regiões do Brasil, ponderaram que o pouco êxito na aquisição de alimentos da agricultura familiar deve-se ao planejamento inadequado do gestor para a execução da compra.

No mesmo âmbito temático, pesquisa realizada nas três capitais da Região Sul do Brasil verificou que em todas era realizada compra de alimentos da agricultura familiar para a alimentação escolar. Segundo os autores, Florianópolis e Curitiba foram classificadas como regulares quanto a estas compras devido ao seu modelo de gestão mais eficiente, enquanto Porto Alegre foi classificada como ruim devido à gestão inadequada do Programa (GABRIEL; GOULART; CALVO, 2015).

Ao investigarem o tema nos estados de São Paulo (241 municípios), Paraná (37 municípios) e Santa Catarina (75 municípios), Baccarin et al. (2017) observaram grande número de chamadas públicas em que informações fundamentais - como a periodicidade e o número de locais para entrega, assim como os preços a serem pagos - estavam ausentes. Os autores argumentaram que isso desestimula a participação dos agricultores familiares no PNAE, já que eles não conseguem avaliar se compensa do ponto de vista econômico.

Cabe, ainda, mencionar o estudo de Mossmann et al. (2017), que contemplou oito municípios catarinenses de diferentes portes populacionais e situados em diferentes 
regiões do estado. As autoras concluíram que as principais dificuldades ao fortalecimento da inserção da agricultura familiar na alimentação escolar referiam-se ao custo dos produtos da agricultura familiar (segundo a percepção dos gestores), à burocracia para que os agricultores fossem habilitados ao fornecimento, à insuficiência de assistência técnica em relação às demandas dos agricultores, à resistência a mudanças e a fragilidades na organização, tanto por parte dos agricultores quanto dos gestores (MOSSMANN et al., 2017).

Nesse contexto, sublinha-se que os desafios relatados na literatura com relação à interface da alimentação escolar com a agricultura familiar são muitos e de natureza bastante variada, tanto para os agricultores quanto para os gestores públicos e técnicos do Programa. Frente a estes desafios, algumas iniciativas de enfrentamento têm sido desenvolvidas (figura 1). São estas iniciativas que serão apresentadas na próxima seção.

\section{Figura 1 - Desafios à inserção da agricultura familiar no Programa Nacional de Alimentação Escolar (PNAE) e mecanismos de enfrentamento desenvolvidos}

\section{Desafios}

- Logística de distribuição (elevado número de pontos de entrega, elevada frequência de entrega, adequação do transporte).

- Chamadas públicas pouco divulgadas, com falta de informações importantes, publicadas com pouca antecedência.

- Assistência técnica (insuficiente, pouco focada na agricultura familiar)

- Falta de interesse dos agricultores, falta de organização para o atendimento das demandas, fallhas no cumprimento dos projetos/contratos de venda.

- Burocracia (falta de documentação dos agricultores, dificuldades de formalização das agroindústrias familiares, de habilitação e

certificação dos agricultores, dificuldades dos agricultores no atendimento das normativas sanitárias).

- Financeiros (atrasos no pagamento pelas prefeituras; custos de produção/adequação/transporte/certificação/associação em cooperativas; preços não vantajosos).

- Estruturais (condições de armazenamento e preparo nas escolas, pouco pessoal para manipulação e preparo de alimentos menos processados).

- Problemas com a qualidade, regularidade, variedade e padrão dos produtos.

- Pouca articulação entre demanda e oferta: demanda maior do que a oferta, descompasso entre cardápios escolares e disponibilidade de produtos e entre o calendário letivo e a disponibilidade de produtos.

- Resistências: dos agricultores às adequações necessárias para o atendimento ao PNAE; dos gestores à dispensa de licitação.

- Pouca compreensão dos diferentes atores sobre o PNAE; falta de capacitação dos atores; conflitos entre os atores; pouco diálogo entre os atores e setores envolvidos.

\section{Mecanismos de enfrentamento}

- Diálogo entre os diversos atores; articulação iintersetorial, desenvolvimento de relações de confiança, trabalho coletivo.

- Apoio de instituições de ensino-pesquisa-extensão e de ATER, com melhoria da assistência técnica e ações de formação e capacitação.

- Participação dos agricultores em associações e cooperativas; formalização/habilitação dos agricultores.

- Revisão juridica, planejamento dialógico dos editais de chamada pública.

- Aproximação entre gestores, CAE, agricultores e lideranças locais.

- Vontade politica (empenho, comprometimento, engajamento) dos diversos atores envolvidos.

- Estruturais (investimentos da prefeitura: criação de central de recebimento de alimentos, disponibilização de equipamentos/maquinaria, suporte para irrigação, apoio para organização de cooperativas; investimentos dos agricultores e cooperativas)

Fonte: Elaborada pelas autoras (2017) a partir da literatura que constituiu o corpus de pesquisa ${ }^{4}$. 
Mecanismos de enfrentamento desenvolvidos com vistas à inserção da agricultura familiar na alimentação escolar

As mudanças ocorridas no PNAE com a aprovação da Lei $n^{\circ}$ 11.947/2009 impuseram diversos desafios para os atores sociais envolvidos. No processo de implantação da Lei, conforme obstáculos se apresentam, alternativas para seu enfrentamento e superação vão sendo construídas. Nessa perspectiva, apresenta-se, a seguir, uma compilação dessas iniciativas identificadas na literatura.

Soares et al. (2015), em estudo realizado em um município do estado de Santa Catarina, sobre as potencialidades e dificuldades para o abastecimento da alimentação escolar por meio da compra de alimentos da agricultura familiar, destacam que o diálogo entre os diversos atores sociais e a aproximação da Secretaria de Educação com as cooperativas foi uma alternativa encontrada para superar as dificuldades.

Da mesma forma, o estudo de Triches e Schneider (2010), realizado em municípios do Rio Grande do Sul, evidenciou a importância da articulação dos diversos atores sociais envolvidos na compra de produtos da agricultura familiar para o PNAE. Os autores argumentam que essa articulação proporcionou o estabelecimento de relações de confiança entre prefeitura e agricultores.

A atuação intersetorial também foi a alternativa encontrada no município de São Bernardo do Campo/SP para adequar a participação da agricultura familiar no PNAE, conforme aponta estudo de Belik e Chaim (2012), em que a articulação entre os setores possibilitou a ampliação do fornecimento de alimentos e a melhoria da qualidade dos produtos. Os mesmos autores, em estudo sobre a gestão do PNAE, realizado em 670 municípios de todas as regiões do Brasil, verificaram como potencialidade o empenho das prefeituras em envolver os produtores, as associações e as cooperativas locais no mercado institucional de compra de alimentos para a alimentação escolar. Esse esforço se traduziu
Revista Grifos 49

4 Literatura que constituiu o corpus de pesquisa: Bacarin et al., 2011; Bacarin et al., 2012; Bacarin et al., 2017; Bavaresco e Mauro, 2012; Belik e Chaim, 2009, 2012; Bevilaqua e Triches, 2014; Bezerra et al., 2013, Cavalheiro, Senna e Ribeiro, 2016; Gabriel, Goulart e Calvo, 2015; Gregolin et al., 2016; Mosimann, 2014; Mossmann e Teo, 2017; Mossmann et al., 2017; Prado et al., 2013; Saraiva et al., 2013; Silva et al., 2013; Silva, Dias e Amorim Junior, 2015; Soares et al., 2015; Souza, 2012; Souza et al., 2013; Souza-Esquerdo e Bergamasco, 2014; Szinwelski et al., 2015; Triches e Kilian, 2016; Triches e Schneider, 2010, 2012; Triches e Baccarin, 2016. 
em iniciativas criativas com o apoio de instituições de pesquisa, como os Institutos ou Empresas de ATER dos estados, que possibilitam a organização, o aprimoramento da produção e a participação nos editais para fornecimento à alimentação escolar (BELIK; CHAIM, 2009).

Szinwelski et al. (2015), a partir de estudo realizado no município de Seara/SC, destacam, como potencialidades para enfrentar as dificuldades identificadas, o trabalho conjunto, a redução dos custos e o apoio técnico dado pelas cooperativas, e ressaltam que a parceria com as cooperativas foi fundamental nos casos avaliados, especialmente no que se refere a aspectos burocráticos com os quais, normalmente, os agricultores apresentam pouca familiaridade.

Triches e Schneider (2012), em estudo realizado em Rolante/RS, destacaram como formas de enfrentamento dos desafios a revisão jurídica e a reformulação dos editais, adaptando as exigências documentais de habilitação, especificamente, ao produtor rural, por meio da atuação em conjunto de diversos atores, formação de cooperativas e associações de agricultores familiares e a formalização dos agricultores e seus estabelecimentos, adequando-se os padrões sanitários, com auxílio da Empresa de Assistência Técnica e Extensão Rural (EMATER), que promoveu a intermediação entre as partes. Os autores argumentam que o trabalho coletivo e a vontade dos atores envolvidos de enfrentar os problemas que se apresentavam como empecilhos para inclusão da agricultura familiar no PNAE foram mecanismos fundamentais nesse contexto.

O estudo de Sousa et al. (2013), sobre a alimentação escolar em comunidades quilombolas do estado de Goiás, identificou como mecanismos de enfrentamento o estabelecimento de parcerias em nível local, a compreensão desse processo como sendo de caráter intersetorial e a necessária aproximação e o diálogo com as lideranças locais, constituindo um espaço coletivo de aprendizagens mútuas. As estratégias identificadas contemplam a realização de oficinas nos territórios das comunidades quilombolas para 
discutir com os agricultores familiares a comercialização dos gêneros alimentícios produzidos para a alimentação escolar, atendendo ao proposto na legislação do PNAE.

O diálogo entre os diversos atores sociais envolvidos e a organização dos agricultores familiares em cooperativas e associações foram identificados como aspectos fundamentais para superar as dificuldades com relação à compra de produtos da agricultura familiar para o PNAE, segundo Mosimann (2014), possibilitando a inclusão de novos agricultores no mercado e a ampliação de seus espaços de fornecimento para outros municípios.

A organização também foi relatada por Souza (2012), em estudo desenvolvido a partir de pesquisas do Projeto SP Nutre. A autora identificou que a organização dos agricultores, formando centrais de cooperativas, possibilitava a comercialização dos produtos para uma área abrangente, incluindo um número maior de municípios. Contudo, a autora alerta que essa alternativa demanda a formação de uma rede entre as cooperativas e associações de uma mesma região, em que sejam realizadas atividades em conjunto, tais como o planejamento da produção, elaboração dos projetos de venda, operações logísticas e compartilhamento de estruturas como barracões de armazenamento, meios de transporte e unidades de processamento, como forma de diminuir as despesas e otimizar a produção.

Nesse contexto, Bezerra et al. (2013), em estudo sobre a aquisição de produtos da agricultura familiar para a alimentação escolar em Minas Gerais e no Espírito Santo, evidenciaram a organização dos agricultores familiares em associações e cooperativas como forma de enfrentar as dificuldades relacionadas a esse mercado. Os autores ainda destacaram que o êxito observado nos municípios pesquisados era devido ao comprometimento dos gestores do Programa (BEZERRA et al., 2013).

Bevilaqua e Triches (2014), ao investigarem a venda de gêneros alimentícios ao PNAE por agricultores familiares, em dois municípios do estado do Paraná, consideraram como 
mecanismo de enfrentamento adotado a articulação dos atores sociais que apresentaram preocupação com a qualidade do produto ofertado, planejamento adequado da produção e empenho em superar o mínimo de compra determinado pela Lei. Para os agricultores, a venda para o PNAE é vista como vantajosa, devido à estabilidade e aos preços fixos, em comparação com outros mercados.

Também como forma de incentivo para a participação da agricultura familiar nesse mercado, algumas políticas vêm sendo implementadas e aperfeiçoadas, dentre as quais se destacam a Política Nacional de Assistência Técnica e Extensão Rural (PNATER), que disponibiliza assistência técnica gratuita com ênfase na gestão dos empreendimentos, e ainda o aumento da oferta de crédito proporcionado pelo Programa Nacional de Fortalecimento da Agricultura Familiar (PRONAF), para que as instituições possam se organizar e armazenar produtos na época de safra, garantindo a regularidade da entrega durante o ano letivo (BAVARESCO; MAURO, 2012).

A orientação técnica e as ações de capacitação foram mecanismos de enfrentamento das dificuldades relacionadas às exigências sanitárias identificados no estudo de Silva, Dias e Amorim Junior (2015), no município de Espera Feliz/MG. Já os agricultores que participaram do estudo de Cavalheiro, Senna e Ribeiro (2016), em São Gabriel/RS, sugeriram, como estratégias para melhorias no processo, a criação de uma central de distribuição, o maior apoio da prefeitura mediante disponibilização de serviços de máquinas, investimentos em irrigação e apoio para a organização de Associações. A esse propósito, Bevilaqua e Triches (2014) consideraram que o êxito observado em seu estudo, no Paraná, era devido justamente à organização dos agricultores em cooperativas e associações.

Outrossim, Belik e Chaim (2012) salientam que a prefeitura de São Bernardo do Campo/SP apresentou experiência exitosa, visto que demonstrou grande capacidade de articulação e diálogo com as organizações de agricultores familiares, tornando-se referência para outros municípios. 
Na mesma direção, Soares et al. (2015), em estudo realizado em um município catarinense, destacaram como potencialidade o engajamento dos agentes locais.

Já um estudo mais recente, desenvolvido em oito municípios do estado de Santa Catarina, corroborou o diálogo e a intersetorialidade, juntamente com ações de capacitação, investimentos da gestão pública e dos agricultores familiares e uma maior organização dos produtores como mecanismos essenciais para o êxito da articulação do segmento com o PNAE (MOSSMANN et al., 2017).

A título de síntese, pondera-se que a Lei no 11.947/2009 abriu um novo mercado para a agricultura familiar comercializar seus produtos, mas - ao mesmo tempo - impôs uma série de exigências para as quais os agricultores não estavam preparados (TEO; MONTEIRO, 2012). Nesta seção, foram destacados alguns estudos que identificaram mecanismos que têm se mostrado eficazes para o enfrentamento destes desafios que se apresentaram à inserção da agricultura familiar no PNAE (Figura 1).

Após oito anos de vigência da Lei, muitos dos desafios apontados ainda persistem, e outros provavelmente surgiram neste período, demandando propor, desenvolver e consolidar mecanismos que favoreçam esse enfrentamento, ressaltando que existem diversas lacunas a serem ainda exploradas no âmbito dessa temática.

\section{O Conselho de Alimentação Escolar (CAE) como parceiro no enfrentamento de desafios}

O CAE é um órgão fundamental para a conquista de avanços na interface da alimentação escolar com a agricultura familiar. Este Conselho, além de seu papel fiscalizador na execução do PNAE, também constitui espaço que pode favorecer a aproximação e o diálogo entre diferentes atores, o que é determinante para a construção coletiva de mecanismos de enfrentamento dos desafios colocados. Assim, é relevante salientar alguns estudos que evidenciam o papel do CAE nesse contexto. 
O estudo de Triches e Schneider (2010), realizado em municípios do Rio Grande do Sul, destaca a importância do CAE como local adequado para a realização de debates e discussões entre diversos atores envolvidos com o PNAE, o que só é possível quando há a interface, diálogo, inter-relação e possibilidade do encontro, oportunizando a superação de dificuldades relacionadas ao Programa. Assim, a aproximação entre diferentes segmentos, no CAE, facilita a criação de uma relação de confiança e proporciona conhecimento mútuo e benefícios todas as partes.

Porém, há estudos em que o $\mathrm{CAE}$ não é referido como um órgão atuante, a exemplo do que foi observado por Mosimann (2014) em estudo desenvolvido em três municípios de Santa Catarina. A autora constatou que, nesses locais, o $\mathrm{CAE}$ era pouco atuante, comprometendo a interação entre os conselheiros e a discussão de assuntos importantes, deixando de exercer sua função de controle social. Nesse estudo, foi constatada a participação de um representante da cooperativa no CAE de um município, o que foi considerado positivo, embora a legislação não exija essa participação. A autora ressalta que a presença de agricultores familiares no $\mathrm{CAE}$ contribuiria para solucionar problemas relacionados à inserção desses atores no processo de fornecimento para a alimentação escolar (MOSIMANN, 2014).

Gabriel, Goulart e Calvo (2015), em estudo realizado nas três capitais da Região Sul do Brasil, identificaram que o $\mathrm{CAE}$ realizava poucas visitas às escolas em todas as capitais, sendo a frequência média inferior a uma visita ao mês no ano de 2011. Além disso, os autores observaram pouco debate a respeito de assuntos relevantes para o PNAE, o que refletiu negativamente sobre a influência prática dos conselhos na melhoria do Programa. Na mesma direção, Gallina et al. (2012), em estudo realizado em um município catarinense, destacam a fragilidade do conhecimento dos conselheiros sobre conceitos fundamentais relacionados à política pública na qual estão inseridos, o que levou as autoras a indicarem a 
existência de um viés de representatividade, em função de um saber sociopolítico ultrapassado.

Machado et al. (2015), em estudo sobre os CAE em municípios catarinenses, identificaram que as funções de controle social no PNAE baseiam-se em seu caráter fiscalizatório e no desempenho de uma função burocrática, destacando pequenos avanços de intervenção na gestão pública devido ao comprometimento individual de alguns conselheiros. Também foi referida a ideia de que o CAE possui uma atuação limitada, pois sua autonomia, estrutura e disponibilidade orçamentária são escassas. Contudo, os autores concluíram que uma atuação mais qualificada é possível, estando na dependência do comprometimento dos conselheiros e do apoio da gestão pública.

Nas experiências bem-sucedidas com a inserção da agricultura familiar no PNAE, percebe-se a gestão compartilhada entre governo e sociedade, identificada a partir da governança conjunta com o CAE e Conselhos de Desenvolvimento Rural. Desse modo, os Conselhos se caracterizariam como locais adequados para o diálogo, favorecendo o encontro de diferentes atores e facilitando o enfrentamento dos desafios que se apresentam (TRICHES; BACCARIN, 2016).

Perante o exposto, evidencia-se a importância do CAE como órgão mediador e promotor do diálogo e do debate entre prefeituras e agricultores e/ou cooperativas para a execução do PNAE. Contudo, a fragilidade de sua atuação ainda é um desafio a ser enfrentado em muitos municípios brasileiros.

\section{Considerações finais}

À guisa de conclusão, pondera-se que os desafios à inserção da agricultura familiar na alimentação escolar e os mecanismos construídos para seu enfrentamento e superação são, em essência, semelhantes nas diferentes regiões do Brasil. Entre estes desafios, destacam-se a logística, a falta de assistência técnica e de interesse dos agricultores e/ou 
prefeituras, a burocracia para a habilitação dos agricultores e sua adequação às normas sanitárias para fornecimento de alimentos, as fragilidades na elaboração das chamadas públicas, as dificuldades financeiras (custos de produção, preços não vantajosos, atrasos nos pagamentos) e estruturais (precárias condições das escolas para o preparo de alimentos menos processados), assim como de organização dos atores envolvidos na execução do PNAE, sua compreensão sobre o Programa e resistências às inovações implementadas no processo de compras públicas. Estes desafios emergiram de forma recorrente, da literatura sobre a temática, como os principais entraves para a consolidação da agricultura familiar como fornecedora de alimentos saudáveis para a alimentação escolar.

Neste sentido, em oito anos de implementação da Lei, muito se avançou na organização deste processo na gestão do PNAE e muitos mecanismos de enfrentamento foram criados. Da análise de literatura realizada, emergiram expressivamente mecanismos como o fortalecimento do diálogo e da articulação intersetorial, o apoio de instituições de ensino, pesquisa, assistência técnica e extensão rural, a organização dos agricultores em associações e cooperativas, o planejamento dialógico das chamadas públicas, a aproximação entre gestores, $\mathrm{CAE}$, agricultores, cooperativas e lideranças locais, os investimentos estruturais do poder público e de agricultores e cooperativas e, sobretudo, a vontade política dos diversos atores envolvidos.

Entretanto, também se evidenciou, a partir da literatura sobre o tema, que ainda é necessária uma maior aproximação entre entidade executora do Programa (gestão pública e técnica) e agricultores, vislumbrando-se um diálogo que proporcione o fortalecimento e a sustentabilidade da agricultura familiar na alimentação escolar. Nesse processo, resta fundamental o amadurecimento do $\mathrm{CAE}$ como um ator importante tanto para o controle social no âmbito do PNAE quanto para a mediação das relações entre os diversos atores envolvidos com a execução do Programa e sua qualificação. 


\section{Referências}

BACCARIN, José Giacomo et al. Alimentação Escolar e agricultura familiar: alcance e dificuldades para implantação do Artigo 14 da Lei 11.947/2009 no Estado de São Paulo. In: CONGRESSO DA SOBER, 49., 2011, Belo Horizonte. Anais... Belo Horizonte: SOBER, 2011.

. et al. Agricultura familiar e alimentação escolar sob a vigência da Lei 11.947/2009: adequação das chamadas públicas e disponibilidade de produtos no estado de São Paulo em 2011. In: CONGRESSO DA SOCIEDADE BRASILEIRA DE ECONOMIA, ADMINISTRAÇÃO E SOCIOLOGIA RURAL, 50., 2012, Vitória. Anais... Vitória: SOBER, 2012. p. 1-20. Disponível em: <http://icongresso.itarget.com.br/useradm/ anais/?clt=ser.2>. Acesso em: 30 nov. 2017.

. et al. Indicadores de Avaliação de compras da agricultura familiar para alimentação escolar no Paraná, Santa Catarina e São Paulo. Revista de Economia e Sociologia Rural (RESR), Piracicaba, v. 55, n. 1, p. 103-122, jan./mar. 2017.

BAVARESCO, Pedro Antônio; MAURO, Fabiana. Agricultura familiar brasileira no Programa Nacional de Alimentação Escolar: garantia de mercado aos agricultores e de segurança alimentar e nutricional aos alunos da rede pública de ensino. In: FÓRUM DE ESPECIALISTAS: PROGRAMAS DE ALIMENTAÇÃO ESCOLAR PARA AMÉRICA LATINA E CARIBE, 2012, Santiago. Anais... Santiago: FAO, 2012. p. 1-7. Disponível em: <http://www.rlc.fao.org/fileadmin/templates/fondobrasil/ documentos/Foro_experto s/Articulos/Artigo_Pedro_Bavaresco. pdf>. Acesso em: 29 set. 2014.

BELIK, Walter; CHAIM, Nuria Abrahão. O programa nacional de alimentação escolar e a gestão municipal: eficiência administrativa, controle social e desenvolvimento local. Revista de Nutrição, Campinas, v. 22, n. 5, p. 595-607, set/out. 2009.

.; _ـ São Bernardo do Campo: atuação pioneira em

favor da agricultura familiar. In: CORÁ, Maria Amélia Junduriam; BELIK, Walter (Org.). Projeto Nutre SP-análise da inclusão da agricultura familiar na alimentação escolar no estado de São Paulo. Brasília: Ministério do Desenvolvimento Agrário, Secretaria da Agricultura familiar, 2012.

BEVILAQUA, Kiara; TRICHES, Rozane Marcia. Implicações da venda de gêneros alimentícios ao Programa de Alimentação Escolar 
nos aspectos de renda e organização dos agricultores familiares. Segurança alimentar e nutricional, Campinas, v. 21, n. 2, p. 448460, jul./dez. 2014.

BEZERRA, Olívia Maria de Paula Alves et al. Promoção da aquisição de produtos da agricultura familiar para a alimentação escolar em Territórios da Cidadania de Minas Gerais e Espírito Santo. Revista de Nutrição, Campinas, v. 26, n. 3, p. 335-342, mai./ jun. 2013.

BRASIL. Ministério da Educação. Fundo Nacional de Desenvolvimento da Educação - FNDE. Lei no 10.696, de 2 de julho de 2003. Dispõe sobre a repactuação e o alongamento de dívidas oriundas de operações de crédito rural, e dá outras providências. Diário Oficial [da] República Federativa do Brasil, Brasília, DF, 3 jul. 2003. Seção 1, p. 1.

- Resolução/CD/FNDE no 38, de 16 de julho de 2009. Dispõe sobre o atendimento da alimentação escolar aos alunos da educação básica no Programa Nacional de Alimentação Escolar (PNAE). Diário Oficial [da] República Federativa do Brasil, Brasília, DF, 17 jun. 2009. Seção 1, p. 10.

Ministério da Educação. Fundo Nacional de Desenvolvimento da Educação. Resolução no 26, de 17 de junho de 2013. Dispõe sobre o atendimento da alimentação escolar aos alunos da educação básica no âmbito do Programa Nacional de Alimentação Escolar - PNAE. Diário Oficial [da] República Federativa do Brasil, Brasília, DF, 18 jun. 2013. Seção 1, p. 7.

. Fundo Nacional de Desenvolvimento da Educação. Dados Agricultura Familiar 2011-2014. Brasília: FNDE, 2015. Disponível em: <http://www.fnde.gov.br/programas/alimentacao-escolar/ alimentacao-escolar-consultas/dados-da-agricultura-familiar $>$. Acesso em: 20 set. 2017.

. Resolução/CD/FNDE no 4, de 2 de abril de 2015. Altera a redação dos artigos 25 a 32 da Resolução/CD/FNDE no 26, de 17 de junho de 2013, no âmbito do Programa Nacional de Alimentação Escolar (PNAE). Diário Oficial [da] República Federativa do Brasil, Brasília, DF, 3 abr. 2015. Seção 1, p. 10.

. Fundo Nacional de Desenvolvimento da Educação. Dados Físicos e Financeiros do PNAE. 1995-2015. Brasília: FNDE, 2017. Disponível em: <http:/www.fnde.gov.br/programas/pnae/ pnae-consultas/pnae-dados-fisicos-e-financeiros-do-pnae >. Acesso em: 20 set. 2017. 
BRUM, Crhis Netto et al. Revisão narrativa da literatura: aspectos conceituais e metodológicos na construção do conhecimento da enfermagem. In: LACERDA, Maria Ribeiro; COSTENARO, Regina Gema Santini (Org.). Metodologias da pesquisa para a enfermagem e saúde: da teoria à prática. Porto Alegre: Moriá, 2016. v. 1. p. 123-142.

BUNDY, Donald et al. Rethinking school feeding: social safety nets, child development, and the education sector. Washington: World Bank, 2009.

BUARQUE, Sérgio. Metodologia de planejamento do desenvolvimento local e municipal sustentável. Brasília, DF: INCRA/IICA, 1999.

CAVALHEIRO, Alex Cesar Marques; SENNA, Ana Júlia Sarmento Barata; RIBEIRO, Ricardo Alves. Análise de fornecimento de produtos da agricultura familiar para o Programa Nacional de Alimentação Escolar (PNAE) no município de São Gabriel-RS. Ciência e Natura, Santa Maria, v. 38, n. 2, p. 906-912, maio/ago. 2016.

CHAVES, Lorena Gonçalves et al. Programa nacional de alimentação escolar compromisso com a saúde pública. Revista Nutrição Profissional, São Paulo, v. 1, n. 22. p. 22-27, abr. 2007.

DOMENE, Semíramis Martins Álvares. A escola como ambiente de promoção da saúde e educação nutricional. Psicologia USP, São Paulo, v. 19, n. 4, p. 505-517, out./dez. 2008.

ESPEJO, Francisco; BURBANO, Carmen; GALLIANO, Elena. Home-Grown School Feeding: A Framework to Link School Feeding with Local Agricultural Production. Rome: WFP, 2009.

FOOD AND AGRICULTURAL ORGANIZATION. Alimentación escolar y las posibilidades de compra directa de la agricultura familiar: estudio de caso de ocho países. Programa de Cooperación Internacional Brasil-FAO. Brasília: Representação da FAO, 2013.

Alimentar o mundo, cuidar do planeta. Montevideo: FAO, 2014.

GABRIEL, Cristine Garcia; GOULART, Gabriela; CALVO, Maria Cristina Marino. Gestão municipal do Programa Nacional de Alimentação Escolar nas capitais da região Sul do Brasil. Revista de Nutrição, Campinas, v. 28, n. 6, p. 667-680, nov./dez. 2015.

GALLINA, Luciara Souza et al. Representações sobre segurança alimentar e nutricional nos discursos de um Conselho de 
Alimentação Escolar. Saúde e Sociedade, São Paulo, v. 21, n. 1, p. 89-102, jan./mar. 2012.

GREGOLIN, Graciela Caroline et al. Participação da agricultura familiar como fornecedora da alimentação escolar no território sudoeste do Paraná. Nucleus, Ituverava, v. 13, n. 1, p. 169-184, abr. 2016.

JARA, Carlos Júlio. A sustentabilidade do desenvolvimento local: desafios de um processo em construção. Brasília: Instituto Interamericano de Cooperação para a Agricultura (IICA); Recife: Secretaria do Planejamento do Estado de Pernambuco (SEPLAN), 1998.

MACHADO, Patrícia Maria de Oliveira et al. Conselhos de Alimentação Escolar em Santa Catarina, Brasil: uma análise do Discurso do Sujeito Coletivo. Revista de Nutrição, Campinas, v. 28, n. 3, p. 305-317, maio/jun. 2015.

MARQUES, Amanda de Andrade et al. Reflexões de agricultores familiares sobre a dinâmica de fornecimento de seus produtos para a alimentação escolar: o caso de Araripe, Ceará. Saúde e Sociedade, São Paulo, v. 23, n. 4, p. 1329-1341, out./dez. 2014.

MOSIMANN, Eloysa Nezello. Agricultura familiar e alimentação escolar nas encostas da serra geral de Santa Catarina: desafios e potencialidades. 2014. 212 f. Dissertação (Mestrado em Agroecossistemas) - Programa de Pós-Graduação em Agroecossistemas, Universidade Federal de Santa Catarina, Florianópolis, 2014.

MOSSMANN, Márcia Pozzagnol et al. Interface Between Family Farming and School Feeding: barriers and coping mechanisms from the perspective of different social actors in Southern Brazil. Revista de Economia e Sociologia Rural, Brasília, v. 55, n. 2, p. 325-342, abr./jun. 2017.

.; TEO, Carla Rosane Paz Arruda. Alimentos da agricultura familiar na alimentação escolar; percepções dos atores sociais sobre a legislação e sua implementação. Interações, Campo Grande, v. 18, n. 2, p. 31-43, abr./jun. 2017.

MOTTER, Adriana Felimberti; TEO, Carla Rozane Paz Arruda. Agricultura Familiar: desafios e dificuldades na reestruturação do Programa Nacional de Alimentação Escolar. In: CONVIBRA SAÚDE, 2., Brasília, 2012. Anais eletrônicos... Brasília: CONVIBRA, 2012. Disponível em: http://www.convibra.com.br/ upload/paper/2012/69/2012_69_4079.pdf. Acesso em: 28 jul. 2017. 
PIRES,Luís Henrique.A descentralização do poder e regionalização das soluções como instrumentos de promoção do desenvolvimento local/regional. In: DOWBOR, Ladislau; POCHMANN, Marcio. Políticas para o desenvolvimento local. São Paulo: Perseu Abramo, 2010. p. 105-130.

PRADO, Tatiana Resende et al. Agricultura familiar na alimentação escolar: estudo de caso em dois municípios de Minas Gerais. Nutrire: Revista da Sociedade Brasileira de Alimentação e Nutrição, São Paulo, v. 38, n. 3, p. 256-268, dez. 2013.

REINACH, Sofia; CORÁ, Maria Amélia Jundurian; BONDUKI, Manuel Ruas Pereira Coelho. A Inclusão da Agricultura Familiar no Programa Nacional de Alimentação Escolar. In: ENCONTRO DA AMPAD, 2012, 36., 2012, Rio de Janeiro. Anais eletrônicos... Rio de Janeiro: ANPAD, 2012. Disponível em: <http://www.anpad.org. br/admin/pdf/2012_APB2404.pdf>. Acesso em 28 jul. 2017.

SANTOS, Fernanda dos et al. Avaliação da inserção de alimentos orgânicos provenientes da agricultura familiar na alimentação escolar, em municípios dos territórios rurais do Rio Grande do Sul, Brasil. Ciência e Saúde Coletiva, Rio de Janeiro, v. 19, n. 5, p. 14291436, maio 2014

SANTOS, Leonor Pacheco et al. Avaliação de políticas de segurança alimentar e combate à fome no período 1995-2002. Programa Nacional de Alimentação Escolar. Cadernos de Saúde Pública, Rio de Janeiro, v. 23, n. 11, p. 2681-2693, nov. 2007.

SARAIVA, Elisa Braga et al. Panorama da compra de alimentos da agricultura familiar para o Programa Nacional de Alimentação Escolar. Ciência e Saúde Coletiva, Rio de Janeiro, v. 18, n. 4, p. $927-$ 935, abr. 2013.

SILVA, Denise Boito Pereira da et al. Os agentes sociais e o Programa Nacional de Alimentação Escolar (PNAE): a percepção dos agricultores familiares. In: ENCONTRO INTERNACIONAL PARTICIPAÇÃO, DEMOCRACIA E POLÍTICAS PÚBLICAS: APROXIMANDO AGENDAS E AGENTES, 2325 abr. 2013, Araraquara. Anais eletrônicos... Araraquara: UNESP, 2013. Disponível em: <http://www.encontropdpp.sinteseeventos. com.br/>. Acesso em: 30 nov. 2017.

SILVA, Márcio Gomes; DIAS, Marcelo Miná; AMORIM JUNIOR, Paula César Gomes. Mudanças organizacionais em empreendimentos de agricultura familiar a partir do acesso ao Programa Nacional de Alimentação Escolar. Revista de Economia e Sociologia Rural, Piracicaba, v. 53, n. 2, p. 289-304, abr.jun. 2015. 
SILVA, Sandro Pereira. Políticas públicas, agricultura familiar e desenvolvimento territorial. Cadernos Gestão Pública e Cidadania, São Paulo, v. 16, n. 58, p. 126-144, jan./jun. 2011.

SILVEIRA, Caio. Desenvolvimento local e novos arranjos socioinstitucionais: algumas referências para a questão da governança. In: DOWBOR, Ladislau; POCHMANN, Marcio. Políticas para o desenvolvimento local. São Paulo: Perseu Abramo, 2010. p. 41-66.

SOARES, Panmela et al. Potencialidades e dificuldades para o abastecimento da alimentação escolar mediante a aquisição de alimentos da agricultura familiar em um município brasileiro. Ciência e Saúde Coletiva, Rio de Janeiro, v. 20, n. 6, p. 1891-1900, jun. 2015.

SOUZA, Liliane Batista Barbosa. Organizações da agricultura familiar no Estado de São Paulo e sua experiência de fornecimento para o PNAE. In: CORÁ, Maria Amélia Jundurian; BELIK, Walter (Org.). Projeto Nutre SP-análise da inclusão da agricultura familiar na alimentação escolar no estado de São Paulo. São Paulo: Instituto Via Pública, 2012.

SOUSA, Lucilene Maria de et al. Alimentação escolar nas comunidades quilombolas: desafios e potencialidades. Ciência e Saúde Coletiva, Rio de Janeiro, v. 18, n. 4, p. 987-992, abr. 2013.

SOUZA-ESQUERDO, Vanilde Ferreira de; BERGAMASCO, Sonia Maria Pessoa Pereira. Análise Sobre o Acesso aos Programas de Políticas Públicas da Agricultura Familiar nos Municípios do Circuito das Frutas (SP). Revista de Economia e Sociologia Rural, Piracicaba, v. 52, supl. 1, p. S205-S222, dez. 2014.

SPINELLI, Maria Angélica dos Santos; CANESQUI, Ana Maria. O programa de alimentação escolar no estado de Mato Grosso: da centralização à descentralização (1979 - 1995). Revista de Nutrição, Campinas, v. 15, n. 1, p. 105-117, jan. 2002.

SZINWELSKI, Nádia Kunkel et al. Implicações do Programa Nacional de Alimentação Escolar (PNAE) na renda e organização de agricultores familiares. Revista Brasileira de Políticas Públicas, Brasília, v. 5, n. 2, p. 220-239 237, jul./dez. 2015.

TEO, Carla Rozane Paz Arruda; MONTEIRO, Carlos Augusto. Marco legal do Programa Nacional de Alimentação Escolar: uma releitura para alinhar propósitos e prática na aquisição de alimentos. Revista de Nutrição, Campinas, v. 25, n. 5, p. 657-668, set./out. 2012.

TRICHES, Rozane Marcia. Repensando o mercado da alimentação escolar: novas institucionalidades para o desenvolvimento rural. In: 
GRISA, Cátia; SCHNEIDER, Sergio (Org.). Políticas públicas

de desenvolvimento rural no Brasil. Porto Alegre: Editora da UFRGS, 2015. p. 181-200.

.; BACCARIN, José Giacomo. Interações entre alimentação escolar e agricultura familiar para o desenvolvimento local. In:TEO, Carla Rozane Paz Arruda; TRICHES, Rozane Márcia (Org.). Alimentação escolar - construindo interfaces entre saúde, educação e desenvolvimento. Chapecó: Argos, 2016. p. 89.

.; KILIAN, Leideliane. Papel dos atores sociais na aquisição de produtos da agricultura familiar para alimentação escolar em municípios paranaenses social. Redes, Santa Cruz do Sul, v. 21, n. 3, p. 159-179, set./dez. 2016.

.; SCHNEIDER, Sergio. Alimentação escolar e agricultura familiar: reconectando o consumo à produção. Saúde e Sociedade, São Paulo, v. 19, n. 4, p. 933-45, out./dez. 2010.

.$; \quad$ D_ Desestruturar para construir: interfaces para agricultura familiar acessar o Programa de Alimentação Escolar. Revista Estudos Sociedade e Agricultura, Rio de Janeiro, v. 20, n. 1, p. 66-106, abr. 2012.

.; ___ SIMÕES, Elsa. Aquisições públicas em Cabo Verde: desafios e potencialidades para promover o desenvolvimento rural. Revista Angolana de Sociologia, Portugal, v. 11, p. 63-80, jun. 2013.

VILLAR, Betzabeth Slater et al. Situação dos municípios do estado de São Paulo com relação à compra direta de produtos da agricultura familiar para o Programa Nacional de Alimentação Escolar (PNAE). Revista Brasileira de Epidemiologia, v. 16, n. 1, p. 223-226, mar. 2013.

Submetido em: 30/10/2017

Aceito em: 13/12/2017 


\title{
CHALLENGES AND COPING MECHANISMS INTHE RELATIONSHIP BE- TWEEN FAMILY FARMING AND SCHOOL FEEDING
}

\begin{abstract}
This paper aims to recognize the challenges that have been reported in the literature regarding the insertion of family farming in the institutional market of school feeding and the coping mechanisms that have been built to overcome these challenges. A literature narrative-review was done with searching in Health Virtual Library, Google Academic and Scientific Electronic Library Online, intersecting "school feeding" and "agriculture". The located materials included were those that met the following criteria: articles, books, dissertations, annals; complete, free and online format; published since 2009; with adherence to the review objective. Among the challenges that emerged, the following stand out: logistics, lack of technical assistance and interest of farmers and/or city halls, bureaucracy to accredit farmers and compliance with sanitary regulations, fragility of public calls, financial, structural and organizational difficulties of the actors involved with the PNAE, their understanding about the Program and resistance to innovations. As for the coping mechanisms constructed, the literature evidenced: strengthening of dialogue, intersectorial articulation, support of teaching/research/technical assistance/rural extension institutions, farmers' organization in associations/cooperatives, dialogical planning of public calls, approximation between managers, School Feeding Councils, farmers and local leaderships, structural investments made by public authorities and farmers/cooperatives and, above all, political will. Despite the advances observed, there is still a need for greater approximation between managers and farmers, as well as for strengthening the School Feeding Council, which can contribute to sustainability of the insertion of family agriculture in school feeding.
\end{abstract}

Keywords: Local Development. Nutrition Programs and Policies. Food and Nutrition Security. 